ments in pregnant sows. On the other hand, on the basis of the piglets' growth between birth and the age of $2 \mathrm{I}$ days, lysine supplementation of the basal diet appeared to be favourable, indicating that the lactation sow has a higher requirement ( $0.69 \mathrm{p}$. Ioo) for this amino-acid. In addition, a significant reduction of the level of urea in the blood of the sows in this experimental group, showed a better utilization of the protein in the diet.

\title{
EFFETS COMPARÉS DE LA LYSINE ET DES MATIÈRES AZOTÉES SUR LES PERFORMANCES DU PORC EN FINITION
}

\author{
Y. HENRY \\ Station de Recherches sur l'Élevage des porcs \\ Centre national de Recherches zootechniques, I. N.R. A., \\ 78350 Jouy en Josas
}

\section{RÉSUMÉ}

L'utilisation accrue, pour le porc en croissance-finition, de régimes à base de maïs, céréale pauvre en matières azotées, et de tourteau de soja, complément azoté riche en lysine, a conduit à une élévation de la teneur en lysine, parallèlement à celle des matières azotées nécessaires à l'obtention de carcasses maigres.

Pour dissocier l'effet propre de la lysine de celui de l'apport azoté global, deux expériences ont été réalisées sur des porcs en finition (entre 60 et $90 \mathrm{~kg}$ de poids vif), portant sur la complémentation d'un régime à base de maïs par du tourteau de soja seul, ou en association avec une source azotée de qualité médiocre, pauvre en lysine (gluten de maïs ou farine de plumes).

Les résultats montrent que l'élévation du taux de matières azotées de 15 à $\mathrm{i} 8 \mathrm{p}$. Ioo dans les régimes renfermant 0,7 p. Ioo de lysine permet d'obtenir chez les femelles une amélioration de la qualité des carcasses, mais non chez les mâles castrés. Cet effet résulte d'un apport supplémentaire d'azote indifférencié, indépendamment du taux de lysine, correspondant à la couverture du besoin en cet acide aminé.

\section{SUMMARY}

\section{COMPARATIVE EFFECTS OF IYSINE AND CRUDE PROTEIN ON PERFORMANCES OF FINISHING PIGS}

The increased utilization, in growing-finishing pigs, of diets based on maize (a low crude protein cereal) and on soya-bean oil meal (a high-lysine feed) has led to a greater proportion of lysine in the crude protein which is necessary to obtain lean carcasses. 
To dissociate lysines's own effect from that of the total protein supply, two trials have been carried out on finishing pigs (between 60 and $90 \mathrm{~kg}$ live weight) to study the supplementation of a maize diet with either soya-bean oil meal alone, or combined with a low-quality protein source, poor in lysine (maize gluten or feather meal).

The results show that raising the crude protein content from $\mathrm{I} 5$ to $\mathrm{r} 8 \mathrm{p}$. Ioo in diets containing 0.7 p. Ioo lysine leads to improvement of the carcass quality in females, but not in castrated males. This effect is due to a supplementary supply of non-specific nitrogen, independent of the lysine level, after satisfying the requirement for this amino acid.

\title{
SUBSTITUTION A UN RÉGIME « MAÏS + SOJA ", SOIT DE MAÏS « RICHE EN LYSINE », SOIT DE LEVURES CULTIVÉES SUR ALCANES ET DE TOURTEAU DE COLZA FERMENTÉ; ESSAI SUR « LARGE WHITE » ET SUR « HYPOR "
}

\author{
A. GAYE et J. MOAL \\ Association générale des Producteurs de Maïs, \\ 64 - Pau
}

RÉSUMÉ

Partant d'un régime " maïs + tourteau de soja cuit " à $\mathbf{1} 7,5$ p. Ioo de matières azotées brutes (MAB) et $0,96 \mathrm{p}$. Ioo de lysine, les auteurs essaient deux types de substitution, à niveau de lysine constant $(0,96)$ sur 16 porcs par régime, nourris semi ad libitum en loges individuelles de 25 à I03 $\mathrm{kg}$ de poids vif.

I. Emploi de maïs "riches en lysine" (sélections en cours de l'I. N. R. A. Clermont-Ferrand) et / ou de lysine de synthèse. Les performances d'élevages sont extrêmement voisines, mais les carcasses sont d'autant plus grasses que le taux de MAB décroît ( 7 7,5 à I $5, \mathrm{I})$. Les maïs riches en lysine semblent d'intêrêt limité (le maïs passe de $7 \mathrm{I}, 6$ à $75,8 \mathrm{p}$. Ioo du régime).

2. Emploi de levures d'alcanes (Sté BP) et de tourteau de colza fermenté. Un régime à 83,8 p. Ioo de mais et 13,2 p. Ioo de levures, assure les mêmes performances d'élevage que le témoin et des carcasses meilleures, bien que le pourcentage de MAB soit réduit à $I 6,2$. Dans le deuxième cas, la croissance est très ralentie $(634 \mathrm{~g} / \mathrm{jour}$ contre $76 \mathrm{r})$ et l'indice de consommation (IC) est très élevé $(3,88 \mathrm{~kg}$ contre 3,28$)$.

Tous régimes confondus, les "Hypor " ont consommé et crû moins que les Large White (IC équivalents) ; leurs carcasses étaient beaucoup plus belles, mais certains d'entre eux ont beaucoup souffert au cours de leur transport à l'abattoir.

Pas d'interaction régimes $x$ types de porcs. 